\title{
CONTROLE SOCIAL E PENAL DE ADOLESCENTES NO BRASIL E NOS EUA
}

SOCIAL CONTROL AND PENALTY OF ADOLESCENTS IN BRAZIL AND IN THE USA

\section{Silmara Carneiro e Silva', Elizabeth Trejos-Castillo², Douglas Dal Molin ${ }^{3}$}

RECEBIDO EM: 26/03/2020 | ACEITO EM: 11/05/2020

DOI: $10.5902 / 2317175843125$

\section{RESUMO}

O objetivo deste artigo é refletir sobre o controle social e penal de adolescentes em conflito com a lei no Brasil e nos Estados Unidos da América - EUA. A pesquisa é de natureza bibliográfica e documental, pautada em autores das ciências sociais e criminológicas que estudam o tema e em dados quantitativos oficiais sobre as respectivas populações de adolescentes em conflito com a lei, em ambos os países. Os resultados apontam para um entrelaçamento das ações de controle social e penal tanto nos EUA como no Brasil, dando-se ênfase ao caráter punitivo, em detrimento da educação e proteção. Verificou-se que há um padrão seletivo no exercício do controle social e penal, que leva em consideração a questão étnico-racial e social.

Palavras-chave: Controle social e penal. Adolescente em conflito com a lei. Seletividade. Subalterno.

\footnotetext{
1 Professora Adjunta do Departamento de Serviço Social e do Programa de Pós-graduação em Ciências Sociais Aplicadas na Universidade Estadual de Ponta Grossa. Lider do Núcleo de Pesquisa Estado, Políticas Públicas e Práticas Sociais da UEPG, Membro do "Positive Youth Development Lab - Texas Tech University - TTU.

2 Psicóloga. Mestre em Sociologia Rural e Doutora em Desenvolvimento Humano e Estudos da Família pela Universidade de Auburn - EUA. Professora da 'Texas Tech University' - TTU - EUA. Pesquisadora líder do 'Positive Youth Development Lab' - TTU - EUA.

3 Psicólogo. Mestre em Ciências Sociais Aplicadas pela Universidade Estadual de Ponta Grossa - UEPG - Brasil. Professor da Faculdade de Telêmaco Borba - FATEB e da Universidade do Norte do Paraná - UNOPAR.
} 


\section{ABSTRACT}

The purpose of this article is to reflect on the social and penal control of adolescents in conflict with the law in Brazil and in the United States of America. The research is of a bibliographic and documentary nature, based on authors of the social and criminological sciences who study the subject and on official quantitative data on the respective populations of adolescents in conflict with the law, in both countries. The results point to an intertwining of social and criminal control actions both in the USA and Brazil, with emphasis on punitive character, to the detriment of education and protection. It was verified that there is a selective pattern in the exercise of social and penal control, which takes into account the ethnic-racial and social question.

Keywords: Social and penal control. Adolescent in conflict with the law. Selectivity. Subaltern.

\section{Introdução}

Os padrões de sociabilidade vigentes são atravessados por diversos projetos econômicos, políticos e sociais, os quais são entrecortados por um conjunto de relações interculturais. Notadamente, os projetos hegemônicos são os que determinam tais relações, imprimindo nelas uma direção. Nas sociedades capitalistas, um padrão conservador de relações sociais é erguido sob os auspícios de um modelo estrutural baseado na divisão de classes e em processos de estratificação social, que se pautam pela desigualdade econômica e social. Nesse modelo, a produção e reprodução das relações sociais são baseadas na lógica de expropriação do excedente de trabalho. A administração desta lógica capitalista é levada a cabo pelo Estado em articulação com o mercado. Além dos fatores econômico e social, as questões culturais e políticas também influenciam na formatação das estruturas estratificadas da sociedade.

Assim, o padrão de desenvolvimento econômico, imposto pelo capitalismo que é global, somado às particularidades políticas, sociais e culturais dos territórios nacionais, repercute na adoção de padrões de administração das relações sociais próprios nos diferentes países.

Inscritas nesse cenário de múltiplas variáveis, as ações de controle social e penal fazem parte do padrão de administração das relações sociais construídas pelos Estados. Tem-se, nesse processo, a parametrização dos comportamentos conforme as expectativas geradas pelos projetos hegemônicos em todo da sociedade. Desse modo, grupos sociais que não correspondem ao padrão hegemônico de comportamento social passam a ser considerados perigosos para a sociedade e indesejáveis ao capitalismo. O controle social e penal das populações nos diferentes países passa a ser uma condição sem a qual é impossível haver condições favoráveis para a reprodução ampliada do capital. Portanto, o trabalho, a livre circulação de mercadorias, a política social e a 
política criminal devem andar de mãos dadas. Mascaro (2013, p. 18) afirma que "O Estado, assim, se revela como um aparato necessário à reprodução capitalista, assegurando a troca das mercadorias e a própria exploração da força de trabalho sob forma assalariada." O entrelaçamento das ações econômicas, políticas, sociais, culturais e penais é um imperativo aos governos no exercício da administração das relações sociais que demanda não somente políticas de inclusão social, como também de controle dos comportamentos em diferentes países. Para tanto, não se negligencia a política, a cultura e as formas históricas de controle social e penal estruturadas pelos Estados, pois elas dizem respeito aos modos como os países respondem aos projetos hegemônicos de reprodução ampliada do capital global.

Considerando que Brasil e Estados Unidos da América-EUA possuem ambos uma história de desigualdades, processos de estratificação social e de exclusão étnico-racial (ALEXANDER, 2017), é pertinente refletir sobre suas ações de controle social e penal nesta direção. Além das questões culturais e sociais, deve-se levar em conta a configuração política de ambos os países. Historicamente tiveram grande influência liberal conservadora. Conquanto, na realidade atual dessas nações, depois de um período curto de governos mais progressistas, retorna ao poder o conservadorismo político. Desta vez, com implantação de uma política de matiz ultraconservadora, amplamente favorável ao arroxo das ações de controle social e penal, cuja feição revelou políticas de governo reforçadoras de posturas discriminatórias das diversidades identitárias e de grupos minoritários. (LACERDA, 2019).

Diante de tais pressupostos, considera-se pertinente refletir sobre as ações de controle social e penal no Brasil e nos EUA e seus reflexos na forma como se delineia o controle estatal de seus adolescentes.

Não há neste trabalho a pretensão de se desenvolver uma análise comparada, o que demandaria um esforço maior e mais sistemático, buscando semelhanças e diferenças, conquanto realizar reflexões sobre os elementos que aproximam os dois países no que diz respeito à direção das ações de controle social e penal assumida pelos governos em face de suas populações juvenis. Assim sendo, alertando para a necessidade de se problematizar a necessidade de se manter atento a essas realidades no mundo, informando programas de prevenção, intervenção e atendimento a este público específico nos diferentes países.

A pesquisa é de natureza bibliográfica e documental; apresenta uma reflexão teórica, pautada em autores que discutem sobre controle social e penal e de autores que abordam o tema dos adolescentes em conflito com a lei. À luz desse referencial, apresenta dados quantitativos referentes ao perfil das populações encarceradas em ambos os países, focando em dados documentais sobre o público adolescente.

Os dados são provenientes de estudos publicados nos EUA e no Brasil e ainda de documentos que apresentam estatísticas advindas de banco de dados oficiais de ambos os países, como do Departamento de Justiça dos EUA, 
"National Center of Juvenile Justice" e do banco de dados 'Bureal of Justice Statistics' e, no Brasil, da Secretaria Nacional de Direitos Humanos, da Presidência da República.

\section{Brasil e EUA: seletividade e controle social e penal do subalterno}

Historicamente, Brasil e EUA construíram sistemas de atendimento públicos pautados em padrões de proteção conservadores, uma vez que o padrão hegemônico da política nesses dois países é, em tendência histórica, de matiz liberal conservadora. Esse padrão político hegemônico tem, cada vez mais, tomado proporções alarmantes na atualidade. Um exemplo disso foi a eleição presidencial de Donald Trump nos EUA e de Jair Messias Bolsonaro, no Brasil, ambos representantes de parcelas ultraconservadoras das respectivas populações nacionais e, por que não dizer, da onda neoconservadora mundial. (LACERDA, 2019).

Representantes dos interesses das elites dirigentes de caráter conservadoras, governos de direita quando assumem o poder, costumam enrijecer as ações de controle social e penal, direcionando esse controle às populações subalternas de seus países, pois são delas aqueles indivíduos considerados 'indesejáveis do sistema capitalista de mercado'. Quem são os subalternos? Aqueles que prescindem de condições econômicas para sua autonomia em sociedade. Ou seja, são aqueles que dependem do Estado e do Mercado para a sua sobrevivência - são pertencentes à classe de trabalhadores.

O fenômeno da subalternização de povos e grupos sociais é, portanto, uma expressão das relações sociais, políticas e econômicas, estruturalmente organizadas no capitalismo. Neste sentido, o controle social e penal de grupos subalternos é uma necessidade estrutural do capital. Assim, torna-se um imperativo aos governos que estão alinhados com uma perspectiva política e econômica compromissada com a reprodução ampliada do capital, pois é da lógica do capital a administração das populações excluídas do processo de mercantilização das relações sociais.

Subalternas são, portanto, aquelas populações que porque indexáveis ao capital, passam a ser vistas como perigosas para a sociedade. A inserção precária no mercado de trabalho e o encarceramento das ditas 'populações perigosas' são ambas saídas consideradas efetivas no rol de ações de controle social e penal lançadas, cotidianamente, contra suas populações subalternas, por governos de matiz conservadora. Os subalternos são desagregados, vulneráveis e dependentes do Estado e do Mercado para se realizarem socialmente. Assim, a "[...] falta de coesão e de organização torna os subalternos politicamente impotentes e incapazes de dar uma expressão centralizada às suas aspirações e às suas necessidades [...] suas rebeliões são destinadas ao fracasso" (BUTTIGIEG IN LIGUORI; VOZA, 2017, p. 749).

Tidos como 'os indesejáveis do sistema' são, nessa perspectiva, os subalternos - aqueles que, não organizados e desagregados, sucumbem diante dos 
projetos hegemônicos. Sua inclusão precária nas relações de mercado, ou faz do subalterno um ser subserviente à dominação econômica; ou o faz 'perigoso' para o sistema, na medida em que se rebela. Nesta situação, os subalternos se tornam, nas palavras de Wacquant (2015), os 'dejetos humanos da sociedade de mercado', indo parar na lata de lixo judicial, chamada prisão.

Neste sentido, as políticas de controle penal e social embora não sejam eficientes do ponto de vista da reeducação e reinserção social dos subalternos, são legitimadas pela sociedade, pois atendem ao clamor daqueles que pedem por segurança pública. (AMARAL, 2011). As múltiplas vulnerabilidades que acometem os subalternos são tidas como fatores que legitimam o controle social e penal. Um exemplo disso é o controle penal em torno da questão das drogas. Segundo Alexander (2017, p. 111)

O percentual de detenções ligadas a drogas que resultaram em condenações à prisão (em condenações quadriplicou, resultando num boom de construção de prisões nunca antes visto. Em duas décadas, entre 1980 e 2000, o número de pessoas encarceradas nas prisões dos Estados Unidos saltou de mais ou menos 300 mil para 2 milhões. No final de 2007, mais de 7 milhões de estadunidenses - ou 1 em cada 31 adultos - estavam atrás das grades ou em liberdade assistida ou condicional.

No Brasil, segundo o Levantamento Nacional de Informações Penitenciárias - Infopen, em 2016, a população carcerária brasileira ultrapassou a população carcerária da Rússia, o que colocou o país na terceira posição no ranking mundial de encarceramento, com 768.700 presos, estando atrás apenas da China, com 1.649.804 presos e dos EUA que possuía uma população carcerária de 2.145.100 presos, à época do levantamento. (BRASIL, Ministério da Justiça, 2016). O aumento da população carcerária brasileira foi de $67,93 \%$ nos quatro últimos anos que precederam a pesquisa, feita em 2017. Isso nos leva a perceber que Brasil e EUA se encontram na mesma rota de encarceramento em massa. $64 \%$ da massa carcerária brasileira é negra e $63 \%$ tem até o ensino fundamental completo, destes $4 \%$ são analfabetos. (BRASIL, 2017). Esses dados revelam a seletividade como um fator presente no padrão de atuação no controle social e penal das populações. Amaral (2011) alerta que no lugar do discurso oficial da reabilitação do indivíduo, próprio do sistema penal, de controle das chamadas 'classes perigosas', emerge na atualidade, a defesa do manejo do risco, da redução dos custos e da intensificação da segurança pública, o que faz a política criminal se entrelaçar ainda mais com a política social, na perspectiva do controle. Wacquant (2015) alerta para uma aproximação empírica e analítica existente entre a política social e a política penal, como uma estratégia do Estado neoliberal.

"A atual preocupação desavergonhada é com a redução do risco de vitimização futura a custo mínimo - o interesse primordial paira indeclinavelmen- 
te pelo 'fortalecimento eficiente do controle social'". (GARLAND, 2005, p. 289 apud AMARAL, 2011, p. 390). A apreensão crítica de alguns dos elementos que sustentam esse entrelaçamento é um desafio em ambos os países analisados neste trabalho.

Fleury; Coppete e Azibeiro (2009) afirmam que a matriz colonial do poder articulou, historicamente, a ideia de raça como instrumento de classificação e controle social. Baratta (2013) afirma que o modelo carcerário adotado nas sociedades capitalistas contemporâneas produz efeitos contrários à reeducação e à reinserção social do condenado. Um estudo realizado pelo IPEA (2015) afirma que no Brasil há muito o que ser superado nas estruturas de atendimento dos estabelecimentos prisionais. A reinserção penal permanece como um problema crucial do sistema e o cárcere é visto como "escola do crime", não há preocupação com a reeducação e tão pouco com o acompanhamento de egressos. (IPEA, 2015).

Amaral (2011) destaca que o volume da população carcerária nos EUA e no Brasil é um problema a ser resolvido. Em 2016, de uma população total de 323.025.335, foram registrados nos EUA um total de 1.506 .800 presos e 6.613.500 encontravam-se sob tutela penal, o que correspondera a $0,47 \%$ da população total do país. (EUA, Bureal of Justice Statistics, 2016).

No Brasil, no mesmo período, de uma população total de 204.450.649, existiam 726.712 pessoas presas em estabelecimentos penais por todo o país, o que corresponde a um percentual de $0,35 \%$ da população nacional. (BRASIL, Infopen, 2017). Nos EUA, a taxa de encarceramento caiu 1\% de 2015 para 2016. No Brasil a taxa de aprisionamento aumentou em 157\%, de 2000 a 2016. (BRASIL, Infopen, 2017).

Novas formas de controle penal estão se estruturando na contemporaneidade, que se apresentam como substitutivas do encarceramento visando controlar os riscos associados, diminuir custos aos Estados e atender às demandas da sociedade por segurança pública, uma vez que atrelam a insegurança pública ao perigo que a população sob tutela penal representa para a sociedade. (AMARAL, 2011). No entanto, em vez de substituir, reforçam as ações de controle tradicionais, sem delas se libertarem. A articulação entre o controle social e o penal é utilizada como estratégia central nessas novas formas de controle que priorizam o meio aberto. (AMARAL, 2011). A generalização da insegurança social se transformou na pedra de toque da política de segurança pública dos EUA desde os anos 1960. Viu-se nos anos 1990 a reconfiguração do Estado Americano em vista da fusão das intervenções da política social e penal, a fim de melhor controlar social e penalmente as populações indesejáveis ao capitalismo de mercado (WACQUANT, 2015).

Imersos neste contexto de repressão, adolescentes em conflito com a lei sofrem com a mão pesada do Estado penal. De acordo com dados disponibilizados pelo Centro Nacional de Justiça Juvenil dos EUA, entre 1960 e 2015, o número de casos de delinquência nos tribunais juvenis mais do que dupli- 
cou (118\%). O modelo assistencial-correcional se fortaleceu no país desde a década 1990 com a reforma assistencial de 1996. Esse modelo compõe um sistema de entrelaçamento da questão social com a criminal, formando um multissistema com objetivos de proteção e punição. Famílias empobrecidas, sem emprego, na maior parte delas de pessoas afrodescendentes e de migrantes latinos, recebem acompanhamento do Estado, recebendo algum tipo de benefício econômico, por até 2 anos, até que encontrem um trabalho (ainda que precarizado). Conquanto, os membros da família que tenham alguma pendência criminal, como aqueles que estão em liberdade condicional, por exemplo, perdem o direito do recebimento de qualquer benefício assistencial por parte do Estado, além de perder o direito ao voto, ou qualquer auxílio para conseguir emprego. As famílias, nessas condições, podem receber auxílio assistencial do Estado por até 5 (cinco) anos, ao longo da vida; depois não há previsão alguma de atenção protetiva estatal, neste sentido. (WACQUANT, 2015). Essa legislação excluiu da assistência social uma variedade de categorias que não possuem poder de pressão política, ou seja, os chamados grupos subalternos. Enquanto mulheres, crianças e adolescentes pobres nos EUA são controlados, socialmente, homens em tais condições, em sua maioria, são controlados penalmente - o que leva ao entrelaçamento do controle social e penal de muitas famílias norte-americanas. (WACQUANT, 2015). Deste modo, o tratamento oferecido aos adolescentes em conflito com a lei não prescinde do modus operandi deste mesmo modelo de atuação multissistêmica (assistencial e correcional). No Brasil, as ações de controle social e penal não são diferentes. A população negra representa $64 \%$ da população do sistema prisional, quando representa $53 \%$ da população total do país. Do total de presos, $4 \%$ são analfabetos e $41 \%$ são pessoas com o ensino fundamental incompleto (BRASIL, Infopen, 2017). O foco em populações pouco escolarizadas é expressão do caráter seletividade social do sistema penal brasileiro, o que se assemelha ao padrão norte-americano.

A pobreza foi e ainda é interpretada como sinônimo de 'vagabundagem'. Portanto, as classes pobres, como representativas das populações subalternas, são foco privilegiado de controle social e penal. No Brasil até 1988 a cidadania era regulada por um padrão que levava em conta a inserção do indivíduo no mercado formal de trabalho. O desempregado, portanto, ficava à mercê de ações de caridade, uma vez que não gozava do status de cidadão. A intervenção do Estado brasileiro variava entre a hostilidade e o apoio a repressão policial e ações assistencialistas e de caridade, sufocando movimentos reivindicatórios, lançando grandes massas ao pauperismo. (IAMAMOTO; CARVALHO, 2008).

Conforme visto, a tendência de criminalização e penalização dos subalternos é, portanto, uma característica de ambos os países analisados. 0 padrão assistencial-correcional tende a restringir benefícios sociais a famílias com membros sob tutela penal. Ao se pensar as medidas correcionais no meio 
aberto, atrela-se as medidas assistenciais à contenção de riscos, à diminuição de custos e às demandas por segurança pública; não há uma preocupação com a finalidade ressocializadora do indivíduo na sociedade, mas com o controle de seu comportamento. A estratégia de articulação de ações de controle social com ações de controle penal é parte das características da cultura penal na contemporaneidade, (AMARAL, 2011), na qual a seletividade é a estratégia central para o controle dos subalternos.

\section{Adolescentes em conflito com a lei no Brasil e nos EUA: aspectos do controle social e penal}

Os EUA é um dos países mais severos no mundo quando se trata da punição de adolescentes. Uma pesquisa desenvolvida nos EUA, em 2012, denominada "The Lives of Juvenile Lifers: Findings from a National Survey" ("As vidas dos jovens que cumprem prisão perpétua: dados de uma pesquisa nacional") aponta que 1.579 pessoas em todo o país que estão cumprindo estas sentenças demonstram altas taxas de desvantagem socioeconômica e disparidades raciais extremas. Estes elementos são considerados na imposição das punições e frequentemente são impostas sentenças sem discrição judicial. (NELLIS, 2012).

Quanto aos casos de 'delinquência juvenil', em 2015, os tribunais americanos com jurisdição juvenil trataram de uma estimativa de 884.900 casos. Dos 884.900 casos de delinquência processados no respectivo ano, $52 \%$ envolveram jovens com menos de 16 anos, $28 \%$ envolveram mulheres e $43 \%$ envolveram jovens brancos (EUA, National Center for Juvenile Justice, 2018). Dos delitos cometidos, o maior percentual foi de natureza patrimonial com $34 \%$; seguido pelos crimes de natureza pessoal com $28 \%$; ofensas a ordem pública, com $25 \%$ e por último os delitos de violação à lei de drogas, com 13\%. Destes 55\% (490.000) dos estimados 884.900 casos judiciais de menores foram tratados formalmente (com a apresentação de uma petição) (EUA, National Center for Juvenile Justice, 2018). Segundo este mesmo levantamento "A proporção de casos de delinquência solicitada diminuiu entre 2005 e 2015 para jovens asiáticos (3 pontos percentuais), permaneceu a mesma para jovens brancos, hispânicos e americanos, e aumentou para jovens negros (até 3 pontos percentuais)."

Dos casos envolvendo jovens negros, houve um aumento de $17 \%$ de casos dispensados judicialmente pelas cortes juvenis para serem tratados pela justiça criminal de adultos durante os anos de 2005 a 2008, depois houve queda de 48\% até 2015. (EUA, National Center for Juvenile Justice, 2018). Dos casos recepcionados pela justiça, verificou-se que os casos de ofensa envolvendo jovens hispânicos eram mais propensos envolver detenção (37\%) do que aqueles envolvendo todas as outras raças. Entre 2005 e 2015, a probabilidade de processamento formal aumentou para os casos envolvendo jovens negros. (EUA, National Center for Juvenile Justice, 2018). Com isso, verifica-se que embora não haja grandes diferenças no cometimento de atos infracionais entre 
as diferentes raças, hispânicos e negros recebem tratamento mais penoso, por parte do país Norte-Americano.

No Brasil, segundo dados do Ministério da Justiça, em 2015, existiam 27.428 adolescentes e jovens em restrição e privação de liberdade no país, o que significa um aumento de 53,6\% em relação ao número de adolescentes nesta mesma condição, em 2009. Destes, $68 \%$ encontravam-se em medida de internação; 9\% em semiliberdade, e 20\% em internação provisória (BRASIL, 2018a). Destes $96 \%$ eram do sexo masculino e $61,03 \%$ foram considerados negros, $23,17 \%$ brancos, $0,81 \%$ amarela, $0,29 \%$ indígenas e $14,67 \%$ sem informações (BRASIL, 2018a). Já o último levantamento, referente ao ano de 2016, mostra que no Brasil existem 26.450 adolescentes e jovens (dos 18 aos 21 anos de idade) atendidos pelo Estado na condição de adolescente em conflito com a lei (BRASIL, 2018b), sendo que, desses, 20.745 estão em cumprimento de internação e restrição de liberdade; 25.360 (96\%) adolescentes do sexo masculino e 1.090 (4\%) do sexo feminino; $59,08 \%$ de cor preta/parda, $22,49 \%$ branca, $16,54 \%$ sem informação, 0,98\% indígena e 0,91\% amarela (BRASIL, 2018b). No mesmo ano, segundo dados do Pnad (2015) apud UNICEF (2017).

2,8 milhões de meninos e meninas ainda estavam fora da escola (Pnad, 2015). E essa exclusão escolar tem rosto e endereço: quem está fora da escola são pobres, negros, indígenas e quilombolas. Uma parcela tem algum tipo de deficiência. E grande parte vive nas periferias dos grandes centros urbanos, no Semiárido, na Amazônia e na zona rural. Muitos deixam a escola para trabalhar e contribuir com a renda familiar.

Os dados acima expostos, sobre o tratamento de adolescentes em conflito com a lei no Brasil, apontam para um aumento de 6,03\%, em um ano, no número de casos restritos e ou privados de liberdade no país, considerando o total de casos atendidos em 2014, que foi de 24.628. Registra-se ainda que a internação de adolescentes em conflito com a lei sofreu aumento, de 8,04\%, o que demonstra um recrudescimento na intervenção judicial, diante dos casos (BRASIL, 2018a). No ano de 2016, do total de adolescentes em conflito com a lei, 70\% (18.567) estavam em medida de internação e 8\% (2.178) em medida de restrição de liberdade (BRASIL, 2018b). Os dados mostram que enquanto a restrição de liberdade teve uma queda, o a privação de liberdade aumentou. Dessa forma, pode-se pensar que os adolescentes ficam mais tempo internados ou que a internação está sendo aplicada com maior frequência do que no ano anterior ao último levantamento. São elementos destacados pela Secretaria de Direitos Humanos (2011) para o crescimento do número de adolescentes em privação e restrição de liberdade durantes as últimas décadas: a construção de unidades socioeducativas; a tendência de aplicar medidas mais severas do Judiciário, mesmo quando não amparada no ordenamento legal e a exposição da população adolescente a territórios que concentram indicadores de violência e expansão do comércio ilícito de drogas (BRASIL, Ipea, 2015). 
Outros motivos são também elencados, como dificuldades do Judiciário em aplicar outras medidas previstas na legislação brasileira, como por exemplo a liberdade assistida e a prestação de serviços comunitários, que são medidas executadas pela política de assistência social. (BRASIL, Ipea, 2015).

Nos EUA, em 2015, foram registrados 216.400 casos de adolescentes presos. Destes $77,1 \%$ eram do sexo masculino e $38 \%$ foram considerados negros e 23\% hispânicos (EUA, Easy Access to Juvenile Court Statistics: 1985-2015, 2018). Adolescentes do sexo feminino sofrem mais com o encarceramento nos EUA, $(22,9 \%)$ do que no Brasil, $4 \%$. Ao contrário, no que se refere ao encarceramento de adolescentes negros, o percentual de encarceramento deste grupo no Brasil é superior em $25 \%$, em relação ao percentual dos EUA, considerado o número total de adolescentes presos. Apesar das diferenças percentuais identificadas, o caráter seletivo racial é característica marcante em ambos os sistemas. Nos EUA, em 2015, “[...] os tribunais juvenis processaram 28,1 casos de delinquência para cada 1.000 jovens na população - aqueles com 10 anos de idade ou mais que estavam sob a jurisdição de um tribunal juvenil" (EUA, National Center for Juvenile Justice, 2018). Mais de 31 milhões de jovens estavam sob jurisdição dos tribunais juvenis em 2015. Destes jovens, 79\% tinham entre 10 e 15 anos, $12 \%$ tinham 16 anos e 9\% tinham 17 anos. De 2008 a 2015 houve uma queda de $44 \%$ nos registros de casos de 'delinquência juvenil', como é denominado no país. A taxa global de casos de delinquência em 2015 foi $46 \%$ abaixo do nível de 2005. (EUA, National Center for Juvenile Justice, 2018). Entretanto, o número de detenções permaneceu alto diante do total de casos registrados, com 216.400 adolescentes detidos em 2015. Este número representa 3,13\% da população juvenil americana, no mesmo ano, que era de 8.309,086 jovens entre 10 a 17 anos (EUA, Easy Access to Juvenile Court Statistics, 2018). Apesar da liberdade condicional ser a sanção mais provável imposta pelos tribunais juvenis nos EUA, registrada em $63 \%$ dos casos, dos 884.900 casos de delinquência juvenil registrados em 2015, 24,45\% sofreram detenção, o que aponta para um alto índice de aprisionamento dos adolescentes em conflito com a lei, no país (NELLIS, 2012). Do total de adolescentes detidos nos EUA, brancos representam 1,2\% do total de adolescentes brancos existentes no país; negros representam $5,9 \%$ do total de adolescentes negros do país; hispânicos detidos representam 2,6\% do total de adolescentes desta mesma etnia e 2,5\% é o percentual de índios americanos detidos em relação ao total de adolescentes indígenas do país (EUA, Easy Access to Juvenile Court Statistics, 2018). Para cada ano entre 2005 e 2015, os casos de delitos de drogas envolvendo jovens negros eram mais propensos a serem peticionados do que aqueles casos envolvendo qualquer outro grupo racial (NELLIS, 2012). Diante dos dados se evidencia que, nos EUA, negros são mais propensos a serem detidos do que outras raças e etnias no país. O percentual de detenção entre os adolescentes brancos é o menor de todos; inferior em 4,7\% em relação aos negros, 1,4\% em relação aos hispânicos e 1,3\% em relação aos índios americanos, apesar dos registros de delinquência juvenil entre adolescentes brancos 
serem superiores aos registros de casos entre adolescentes negros. Do total de casos registrados, $43 \%$ são de brancos e $38 \%$ são de negros. No entanto, a detenção entre adolescentes brancos é de $36 \%$ e de adolescentes negros é de $38 \%$ (NELLIS, 2012). Casos de delinquência envolvendo índios americanos foram mais propensos a resultar em um julgamento de delinquência do que casos envolvendo todas as outras raças e/ou etnias. (NELLIS, 2012). Negros e latinos constituem, assim, a maior parte dos jovens no sistema de justiça juvenil nos EUA, embora sejam a minoria da população jovem americana. (CORNELIUS, 2017).

O perfil de aprisionamento juvenil nos EUA confirma a seletividade étnico-racial como uma característica marcante no sistema penal norte-americano. Em relação aos delitos cometidos pelos adolescentes nos EUA, dentre os casos registrados em $2015,28 \%$ dos casos de delito de pessoa, $34 \%$ de casos de delito de propriedade, $13 \%$ de casos de delito de drogas e $25 \%$ de casos de delito de ordem pública. (EUA, National Center for Juvenile Justice, 2018).

No Brasil, o índice percentual de aplicação de medidas privativas e restritivas de liberdade (medida de internação e semiliberdade), segue da seguinte forma: roubo $47 \%$, seguido pelo tráfico de drogas em $22 \%$ e pelo homicídio, em $10 \%$. Os outros $18 \%$ representam furto (3\%), tentativas de homicídio (3\%), tentativa de roubo (1\%), latrocínio e porte de arma de fogo, $2 \%$ cada, receptação, lesão corporal, estupro, ameaça de morte, em $1 \%$ cada; e outros não especificados (4\%) (BRASIL, 2018b). Diante do perfil infracional apresentado verifica-se que o maior percentual de atos infracionais cometidos no Brasil, em 2016, foi de natureza patrimonial, tendência estatística similar à constatada nos EUA, no mesmo ano, onde este percentual foi de $34 \%$, do total de casos registrados. Quanto ao perfil de renda dos adolescentes restritos e ou privados de liberdade no Brasil, majoritariamente, são adolescentes advindos de "[...] famílias pobres e sem muita expectativa de futuro" (BRASIL, 2012, p. 23).

Diante dos dados, nota-se que a violência patrimonial impera dentre os adolescentes que cometem atos infracionais nos dois países. Trata-se de uma característica marcante de países com altos níveis de desigualdade. No Brasil, por exemplo, em 2017, os "10\% da população com os maiores rendimentos detinham $43,3 \%$ da massa de rendimentos do país, enquanto a parcela dos $10 \%$ com os menores rendimentos detinha $0,7 \%$ desta massa. (BRASIL, IBGE, 2018).

No Brasil, o caráter punitivo presente no tratamento oferecido ao adolescente em conflito com a lei se inscreve, contraditoriamente, no âmbito das políticas de atenção assistencial, que acaba por assumir um caráter assistencial-correcional. Além das medidas socioeducativas de meio aberto, liberdade assistida e prestação de serviços à comunidade, a política de assistência social no Brasil incorpora, ainda, as medidas restritivas e privativas de liberdade, em seus marcos de ação (BRASIL, 2011). Em ambos os casos, as ações se dão por motivação de caráter assistencial-correcional, uma vez que a ação judicial, nestes casos, não se dá por exclusiva motivação protetiva, mas é fruto de uma intervenção estatal de caráter jurídico-sancionatório. 
A legislação especial brasileira prevê a aplicação de medida socioeducativa concomitante a uma ou mais medidas protetivas. Este instrumento jurídico previsto na legislação brasileira,é expressão formal do entrelaçamento do controle social e penal de adolescentes em conflito com a lei do país, o que confirma a natureza difusa do controle exercido pelo Estado brasileiro, em face de seus grupos subalternos. Ao serem acometidos pelo sistema socioeducativo, “[...] meninos, que em muitos casos não possuem acesso a bens e serviços sociais/sanitários/culturais, a adolescentes em conflito com a lei em virtude do ato infracional realizado, sendo então tomados pela rede da justiça" (SCISLESKI et al, 2015, p. 506). Não é por razão diversa que se identifica, no Brasil, o registro majoritário de adolescentes em cumprimento de medidas socioeducativas, que são oriundos de grupos vulneráveis social e economicamente. (BRASIL, 2012).

Entre os adolescentes restritos e ou privados de liberdade no Brasil, registra-se que a maior parte é negra; oriunda de famílias cuja renda é baixa, que cometeram atos infracionais de natureza patrimonial e/ou que possuem alguma relação com o uso e ou tráfico de drogas. (BRASIL, 2018a; BRASIL, 2018b). Os altos índices de aplicação de medidas mais severas, como são as medidas judiciais de privação e de restrição de liberdade e ou de detenção como se denomina nos EUA, identificados em ambos os países investigados, são voltadas às populações subalternas (negros, índios, hispânicos, de baixa escolaridade, usuários de drogas, etc.). Esta postura demonstra a face punitiva e a seletividade étnico-racial e social das ações de controle dos Estados, em face de suas populações. Não sendo esta realidade uma tendência voltada apenas ao público de adolescentes, mas uma tendência geral de ambos os sistemas, nos quais há um entrelaçamento do controle social com o penal, conforme visto nos dados oficiais apresentados anteriormente. Conforme Alexander (2017), o encarceramento em massa e a segregação étnico-racial são características marcantes dos sistemas carcerários, em ambos os países. O gráfico a seguir apresenta dados percentuais comparativos relativos ao público do sistema de justiça juvenil dos EUA e do sistema socioeducativo no Brasil.

Gráfico 1 - Porcentagem comparativa de dados relativos ao público do sistema de justiça juvenil (EUA) e do sistema socioeducativo $(\mathrm{BR})-2016 * *$ *

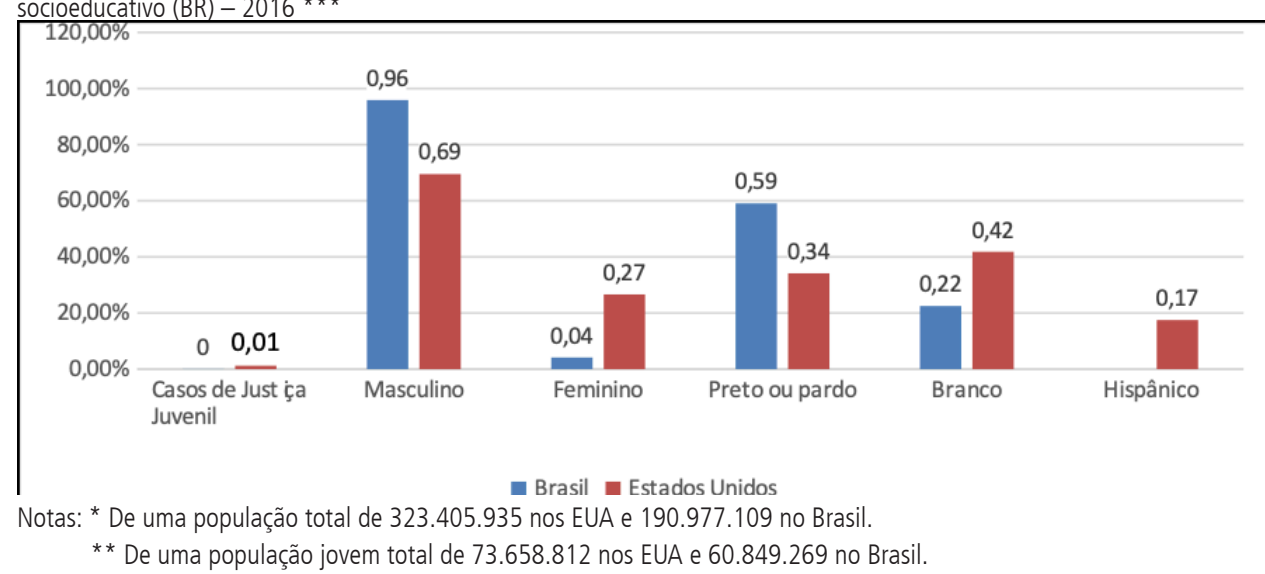

Fonte: Secretaria Nacional de Atendimento Soicoeducativo (BRASIL, 2016); National Center of Juvenile Justice (2018) apud Dal Molin; Trejos-Castillo; Silva (2018) 
De acordo com o gráfico acima verifica-se que o percentual de casos atendidos pela justiça juvenil nos EUA supera os do sistema socioeducativo no Brasil em 1,16\%. No que se refere ao percentual referente ao sexo dos jovens presos em ambos os países, nos EUA $69,48 \%$ são do sexo masculino e $26,62 \%$ são do sexo masculino. $E$, no Brasil, é majoritária a prisão de adolescentes do sexo masculino, com $95,87 \%$ dos casos. O percentual de adolescentes presos de cor preta ou marrom nos EUA é de $34,13 \%$, em relação a $41,83 \%$ de adolescentes brancos e $17,47 \%$ são hispânicos. No Brasil, respectivamente o percentual é de $59,07 \%$ e de $22,48 \%$, o que confirma o corte étnico-racial, com destaque para a prisão de negros. Nos EUA destaca-se, além dos negros, os latino-americanos (DAL MOLIN; TREJOS-CASTILLO; SILVA, 2018).

De modo geral, nota-se que o controle penal exercido pelos EUA sob sua população de adolescentes é superior ao exercido pelo Brasil; que o foco majoritário é de adolescentes do sexo masculino, destacando-se um percentual superior, em 22,5\% nos EUA, em relação às adolescentes, do sexo feminino sob tutela do sistema socioeducativo no Brasil. Quanto à raça, o percentual brasileiro é superior em $24,9 \%$ ao dos EUA, o que significa que o corte racial do sistema socioedutivo brasileiro é maior que o do sistema de justiça juvenil norte-americano, que possui mais brancos sob sua tutela em proporção ao Brasil e agrega ainda os hispânicos, em $17,47 \%$ do total de adolescentes no respectivo sistema.

Em geral, é necessário pensar nas particularidades do controle social e penal dessas populações, sem desvincular o tratamento dos adolescentes das questões estruturais que sustentam a sociedade norteamericana e a brasileira. Importante se faz que cada vez mais sejam problematizadas tais questões, em face do aprimoramento de ações protetivas e do arrefecimento do padrão de controle social e penal exercido seletivamente em face das populações subalternas em ambos os países, em vista da melhoria do atendimento do respectivo público, que é amplamente vulnerável.

\section{Considerações Finais}

Verificou-se que os dois países apresentam padrões de intervenção que articulam o controle social ao controle penal em vista do enfrentamento do perigo que representam os adolescentes em conflito com a lei para a segurança pública, ambos também adotam o encarceramento em massa como estratégia de controle majoritária e mantém-se pautados num padrão de seletividade étnico-racial e social, com foco nos grupos subalternizados de suas populações nacionais, que no caso dos adolescentes seleciona especialmente hispânicos, negros e pobres, usuários de drogas, com baixa escolaridade etc. A forma de atuar se dá por um padrão articulado de ações de caráter correcional-assistenciais.

Novas perspectivas de intervenção estatal têm sido adotadas com reforço ao entrelaçamento do controle social com o penal entre os operado- 
res do sistema penal, na contemporaneidade, com foco no meio aberto como estratégia de contenção dos riscos que as populações tidas como perigosas oferecem para a sociedade. Tais medidas que, conforme visto, subordinam o controle social a critérios de seletividade penal, o que é um grave retrocesso para o campo das políticas públicas (sociais). Necessário se faz pensar em como resistir a essa tendência da cultura penal na contemporaneidade. Trata-se de um desafio posto às políticas públicas nos dois países. Novas metodologias de trabalho, como são, por exemplo, as respaldadas na Teoria Bioecológica do Desenvolvimento, na Pedagogia Social, na Educação para a Paz, na Educação em Direitos Humanos e na Justiça Restaurativa devem ser, cada vez mais, problematizadas, enquanto saídas que podem contribuir para o enfrentamento de tais desafios na atualidade.

\section{Referências}

ALEXANDER, Michele. A nova segregação: racismo e encarceramento em massa. São Paulo: Boitempo editorial, 2017

AMARAL, Augusto Jobim do. A cultura do controle penal na contemporaneidade. Revista Jurídica da Presidência. Brasília, v. 12 n. 28, 2011. Disponível em: https://revistajuridica.presidencia.gov.br/index.php/saj/article/ view/164/157. Acesso em: 14, maio 2018.

BRASIL, Presidência da República. Lei 12.435 de 6 de julho de 2011. Brasília, 2011. Disponível em: http://www. planalto.gov.br/ccivil_03/_Ato2011-2014/2011/Lei/L12435.htm. Acesso em: 13, maio 2018.

BRASIL, Secretaria de Atendimento Socioeducativo. Atendimento Socioeducativo ao Adolescente em Conflito com a Lei: Levantamento nacional 2011. Brasília, 2012. Disponível em: <http://www.sdh.gov.br/assuntos/ criancas-e-adolescentes/pdf/SinaseLevantamento2011.pdf>.

BRASIL, Unicef. Infância e adolescência no Brasil. 2018. Disponível em: https://www.unicef.org/brazil/pt/ activities_9418.html. Acesso em: 03, maio 2018.

BRASIL, Instituto de Pesquisa Econômica Aplicada. O desafio da reintegração social do preso: uma pesquisa em estabelecimentos prisionais. Brasília, Rio de Janeiro, IPEA. 2015. Disponível em: http://repositorio.ipea. gov.br/bitstream/11058/4375/1/td_2095.pdf. Acesso em: 25, maio 2018.

BRASIL, Instituto Brasileiro de Geografia e Estatística. Estatísticas Sociais. 2017. Disponível em: https:// agenciadenoticias.ibge.gov.br/agencia-sala-de-imprensa/2013-agencia-de-noticias/releases/20843-pnadcontinua-10-da-populacao-concentravam-quase-metade-da-massa-de-rendimentos-do-pais-em-2017. Acesso em: 10, maio 2018.

BRASIL, Ministério dos Direitos Humanos (MDH). Levantamento Anual SINASE 2015. 2018a. Brasília: Ministério dos Direitos Humanos.

BRASIL, Ministério dos Direitos Humanos (MDH). Levantamento Anual SINASE 2016. Brasília: Ministério dos Direitos Humanos, 2018b.

BUTTIGIEG, Joseph A. Subalterno/Subalternos. In: LIGUORI, Guido; VOZA, Pasquale (Orgs.). Dicionário gramsciano (1926-1937). 1. ed. - São Paulo: Boitempo, 2017.

CNJ. Regras de Tóquio: Regras Mínimas Padrão das Nações Unidas para a Elaboração de Medidas não Privativas de Liberdade. Brasília. 2016.

CORNELIUS, E. G.. Resenha: Criminalização, racialização e patologização: as origens do sistema de justiça juvenil da Califórnia. PLURAL, Revista do Programa de PósGraduação em Sociologia da USP, São Paulo. 2017, v.24.1, p.185-193. 
DAL MOLIN, D. TREJOS-CASTILLO, E. SILVA, S. C. e. Cross-Border Child Welfare \& Juvenile Justice Systems: The Realities of Brazilian \& United States Multisystem Youth. Poster apresentado no $74^{\circ}$ Annual Meeting: instituições, cultures and crime, Atlanta, 2018.

ESPOSITO, C. L., CLUM, G. A.. Social support and problem-solving as moderators os the relationship between childhood abuse and suicidality: Applications to a delinquent population. Journal of Traumatic Srress, 2002, v. 1, n.. 2, April. pp. 137-146.

EUA. Easy Access to Juvenile Court Statistics: 1985-2015. 2018. Disponível em: https://www.ojjdp.gov/ojstatbb/ ezajcs/asp/demo.asp. Acesso em: 25, jun. 2018.

EUA. Easy Access to Juvenile Populations: 1990-2017. 2018. Disponível em: https://www.ojjdp.gov/ojstatbb/ ezapop/. Acesso em: 25, jun. 2018.

FLEURY. S., COPPETE, M. C; AZIBEIRO, N. E. Pesquisas Interculturais: Descolonizar o Saber, o Poder, o Ser e o Viver In: Culturas e diversidade religiosa na América Latina: pesquisas e perspectivas pedagógicas. São Leopoldo : EDIFURB; Nova Harmonia, 2009, p. 30-46.

GALLAGHER, C. A., DOBRIN, A.. Deaths in juvenile justice residential facilities. Journal of Adolescent Health. 2006, p. 662-668

GRAY, D. M.d. (2002). Utah youth suicide study, phase I: Governmente aagency contact before death. J. AM. ACAD. Child Adolesc. Psychiatry, 2002, v. 41, n. 4, april.

IPEA. $\mathbf{O}$ adolescente em conflito com a lei e o debate sobre a redução da maioridade penal: esclarecimentos necessários. Brasília, jun. 2015. Disponível em: <http://www.ipea.gov.br/portal/images/ stories/PDFs/notatecnica_maioridade_penal>. Acesso em: 28, mai. 2018.

LACERDA, Marina Basso. O novo conservadorismo brasileiro: de Reagan a Bolsonaro. Porto Alegre, RS: Zouk, 2019

MASCARO, A. L. (2013). Estado e forma política. São Paulo: Boitempo editorial, 2013.

MEMORY, J. M . Juvenile suicides in secure detention facilities: Correction of published rates. Death Studies, 1989, v. 13, n. $5,455-463$.

NELLIS, A. The Lives of Juvenile Lifers: Findings from a National Survey. 2018. Disponível em: http:// sentencingproject.org/wp-content/uploads/2016/01/The-Lives-of-Juvenile-Lifers.pdf. Acesso em: 25, jun. 2019.

SCISLESKI, A. C. C., et all. (2015). Medida socioeducativa de internação: estratégia punitiva ou protetiva?. Revista Psicologia \& Sociedade, v. 27, n. 3, p. 505-515. Disponível em: http://www.scielo.br/pdf/psoc/ v27n3/1807-0310-psoc-27-03-00505.pdf. Acesso em: 17, maio 2018.

WACQUANT, L. Punir os pobres: a nova gestão da miséria nos Estados Unidos [a onda punitiva]. Rio de Janeiro: Revan, 2015. 